J. Dairy Sci. 96:3211-3221

http://dx.doi.org/10.3168/jds.2012-6211

(C) American Dairy Science Association ${ }^{\circledR}, 2013$.

\title{
Incremental effect of a calcium salt of cis-monounsaturated fatty acids supplement on milk fatty acid composition in cows fed maize silage-based diets
}

\author{
K. E. Kliem, ${ }^{* 1}$ C. K. Reynolds, ${ }^{*}$ D. J. Humphries, ${ }^{*}$ R. M. Kirkland,† C. E. S. Barratt, ${ }^{*}$ \\ K. M. Livingstone, ${ }^{*}$ and D. I. Givens* \\ *Division of Food Production and Quality, School of Agriculture, Policy and Development, University of Reading, Reading RG6 6AR, \\ United Kingdom \\ †Volac International Ltd., Royston, Hertfordshire SG8 5QX, United Kingdom
}

\begin{abstract}
In most Western countries, saturated fatty acid (SFA) intake exceeds recommended levels, which is considered a risk factor for cardiovascular disease (CVD). As milk and dairy products are major contributors to SFA intake in many countries, recent research has focused on sustainable methods of producing milk with a lower saturated fat concentration by altering dairy cow diets. Human intervention studies have shown that CVD risk can be reduced by consuming dairy products with reduced SFA and increased cis-monounsaturated fatty acid (MUFA) concentrations. This milk fatty acid profile can be achieved by supplementing dairy cow diets with cis-MUFA-rich unsaturated oils. However, rumen exposure of unsaturated oils also leads to enhanced milk trans fatty acid (TFA) concentrations. Because of concerns about the effects of TFA consumption on CVD, feeding strategies that increase MUFA concentrations in milk without concomitant increases in TFA concentration are preferred by milk processors. In an attempt to limit TFA production and increase the replacement of SFA by cis-MUFA, a preparation of rumen-protected unsaturated oils was developed using saponification with calcium salts. Four multiparous Holstein-Friesian cows in mid-late lactation were used in a $4 \times 4$ Latin square design with 21 -d periods to investigate the effect of incremental dietary inclusion of a calcium salt of cis-MUFA product (Ca-MUFA; 20, 40 , and $60 \mathrm{~g} / \mathrm{kg}$ of dry matter of a maize silage-based diet), on milk production, composition, and fatty acid concentration. Increasing Ca-MUFA inclusion reduced dry matter intake linearly, but no change was observed in estimated ME intake. No change in milk yield was noted, but milk fat and protein concentrations were linearly reduced. Supplementation with Ca-MUFA re-
\end{abstract}

Received September 28, 2012.

Accepted January 20, 2013.

${ }^{1}$ Corresponding author: k.e.kliem@reading.ac.uk sulted in a linear reduction in total SFA (from 71 to 52 $\mathrm{g} / 100 \mathrm{~g}$ of fatty acids for control and $60 \mathrm{~g} / \mathrm{kg}$ of dry matter diets, respectively). In addition, concentrations of both cis- and trans-MUFA were increased with CaMUFA inclusion, and increases in other biohydrogenation intermediates in milk fat were also observed. The Ca-MUFA supplement was very effective at reducing milk SFA concentration and increasing cis-MUFA concentrations without incurring any negative effects on milk and milk component yields. However, reduced milk fat and protein concentrations, together with increases in milk TFA concentrations, suggest partial dissociation of the calcium salts in the rumen.

Key words: milk fatty acid, calcium salt, monounsaturated fatty acid, trans fatty acid

\section{INTRODUCTION}

Dietary fat content and composition is considered one of the most important modifiable determinants of cardiovascular disease (CVD) risk, with a 1\% reduction in intake of energy from SFA predicted to result in a 3\% decrease in CVD risk, based on its effect on low density lipoprotein-cholesterol (Givens, 2009). The United Kingdom exceeds its dietary target for SFA intake, by around $10 \%$ on average (Bates et al., 2010). In the United Kingdom, milk and dairy products contribute about $27 \%$ of total SFA consumed (Bates et al., 2010), with higher contributions in other EU countries (Hulshof et al., 1999). Intervention studies have shown that replacing SFA with cis-MUFA in dairy products has favorable effects on serum cholesterol levels, which may lead to a reduction in CVD risk over a longer period (Wood et al., 1993; Tholstrup et al., 1998; Seidel et al., 2005).

Numerous studies have shown the potential of dairy cow nutrition to produce milk with reduced SFA and increased MUFA (e.g., Kirchgessner et al., 1967; Ashes et al., 1992; Jenkins, 1998). A series of studies at the University of Reading demonstrated that the inclusion 
of crushed rapeseeds in the diet of the dairy cow can reduce SFA from 70 to 55 or $60 \%$ of total FA while increasing cis-MUFA from 20 to $33 \%$ of total FA (Givens et al., 2009). However, the increase in cis-MUFA concentration in response to feeding full-fat rapeseed was accompanied by an increase in trans-18:1 concentration, which is a consequence of rumen biohydrogenation of the rapeseed oil fed. An alternative approach is to feed rumen-protected sources of cis-MUFA, which should minimize the development of trans-monoenes and maximize the increase in cis-MUFA concentration in milk. In previous studies, a variety of approaches have been used to reduce the rumen biohydrogenation of rapeseed or canola oil FA with varying success (e.g., Chouinard et al., 1997; Enjalbert et al., 1997). Calcium salts of canola oil FA have been effective in elevating cis-MUFA concentration of milk (Ferlay et al., 1992), but not without an increase in trans-isomer concentrations (Enjalbert et al., 1997; Chouinard et al., 1997, 1998), suggesting that Ca-salts of FA from rapeseed or canola oil are at least partially susceptible to rumen biohydrogenation. This may be due in part to the differences in the dissociation constant of the Ca-salts formed, which vary with the degree of their unsaturation (Chouinard et al., 1997 and 1998).

The objectives of the present study were to measure the effect of feeding increasing amounts of a Ca-salt of high cis-MUFA on feed intake, milk yield and composition, and milk FA composition in lactating Holstein cows.

\section{MATERIALS AND METHODS}

\section{Design, Animals, and Management}

The effect of incremental doses of a high-C18:1 Casalt product was measured using a balanced $4 \times 4$ Latin square design experiment with 21-d experimental periods. Four multiparous, mid- to late-lactation HolsteinFriesian cows were used with (mean $\pm \mathrm{SE}$ ) liveweight of $727 \pm 23.0 \mathrm{~kg}$, parity of $5.8 \pm 0.75$, milk yield of $29 \pm$ $2.9 \mathrm{~kg} / \mathrm{d}$, and $244 \pm 25.1$ DIM at the start of the study. Cows were house in individual tiestalls equipped with a rubber mattress and bedded with wood shavings. Clean water and trace mineralized blocks (Rockies, Tithebarn Ltd., Cheshire, UK) were available ad libitum. Cows were milked in situ at $0530 \mathrm{~h}$ and $1530 \mathrm{~h}$.

\section{Experimental Diets}

Diets were offered as a TMR using computerized feeders (Insentec, Marknesse, the Netherlands; forage:concentrate ratio 50:50 on a DM basis) with the forage component consisting of maize silage and grass silage (750 and $250 \mathrm{~g} / \mathrm{kg}$ of forage DM, respectively). Treatments consisted of a control diet containing no supplemental lipid (control) or the same basal diet with Ca-salts containing a high proportion of cis-MUFA (Ca-MUFA; Volac International Ltd., Royston, UK) fed at incremental inclusion rates of 20,40 , and $60 \mathrm{~g} /$ $\mathrm{kg}$ of ration DM (CS2, CS4, and CS6, respectively), to provide supplement intakes of 440, 880, and $1320 \mathrm{~g} /$ day at a predicted mean daily DM intake of $22 \mathrm{~kg}$. The supplement was produced by industrial saponification of an 18:1-rich oil, resulting in a vigorous reaction leading to a product rich in fine particles. The supplement was incrementally included in rations over the first 4 $\mathrm{d}$ of each experimental period. Ingredients and chemical composition of the experimental diets are shown in Table 1. The supplements were added to the basal TMR, rather than replacing specific components, and thus diluted the other ingredients proportionally. Feed refusals were removed and weighed before the morning milking.

\section{Experimental Measurements, Sample Collection, and Chemical Analysis}

Feed intake was recorded daily. Representative samples of the $4 \mathrm{TMR}$, individual forages (maize silage, grass silage) and concentrates [concentrates, Sopralin (Trouw Nutrition, Belfast, UK), Ca-MUFA] were taken on d 16 to 20 of each experimental period, bulked and stored in sealed bags at $-20^{\circ} \mathrm{C}$. A representative sample of refused feed was taken during the last $5 \mathrm{~d}$ of each experimental period and analyzed for DM content $\left(100^{\circ} \mathrm{C}\right)$ to determine individual DM intakes. Samples of forages and concentrates were stored frozen until analyzed for NDF, ADF, OM, CP, water-soluble carbohydrates, starch, and estimated ME concentrations according to reference procedures as outlined elsewhere (Kliem et al., 2008).

Milk yields were recorded daily throughout the study. Samples of milk preserved with potassium dichromate (1 mg/mL, Broad Spectrum Microtabs, D\&F Control Systems Inc., Dublin, CA) for the determination of fat, $\mathrm{CP}$, and lactose by infrared spectroscopy (Milkoscan FT6000 infrared analyzer, Foss Ltd., Warrington, UK) were collected during the last $3 \mathrm{~d}$ of each experimental period. Additional samples of unpreserved milk were also collected on the last day of each period and stored at $-20^{\circ} \mathrm{C}$ until composited according to yield, and submitted for FA analysis.

Lipids in $1 \mathrm{~mL}$ of milk and appropriate sample weights of forage, concentrate, and lipid supplement samples was extracted and transesterified to fatty acid methyl esters (FAME), and then FAME were separated using standard methods (Kliem et al., 2008). 
Table 1. Ingredients and chemical composition of experimental diets ( $\mathrm{g} / \mathrm{kg}$ of DM or as stated)

\begin{tabular}{|c|c|c|c|c|}
\hline \multirow[b]{2}{*}{ Item } & \multicolumn{4}{|c|}{ Treatment $^{1}$} \\
\hline & Control & CS2 & CS4 & CS6 \\
\hline \multicolumn{5}{|l|}{ Ingredients } \\
\hline Maize silage & 375 & 367.6 & 360.6 & 353.8 \\
\hline Grass silage & 125 & 122.5 & 120.2 & 117.9 \\
\hline Maize meal & 162 & 158.8 & 155.8 & 152.8 \\
\hline Soybean meal & 100 & 98.0 & 96.2 & 94.3 \\
\hline Sugar beet pulp, molassed & 112 & 109.8 & 107.7 & 105.7 \\
\hline Wheat feed & 45 & 44.1 & 43.2 & 42.4 \\
\hline Molasses & 15 & 14.7 & 14.4 & 14.2 \\
\hline Salt $^{2}$ & 5 & 4.9 & 4.8 & 4.7 \\
\hline Minerals ${ }^{3}$ & 10 & 9.8 & 9.6 & 9.4 \\
\hline Protected soybean meal $^{4}$ & 46 & 45.1 & 44.2 & 43.4 \\
\hline Dicalcium phosphate & 5 & 4.9 & 4.8 & 4.7 \\
\hline Ca-salts of cis-MUFA ${ }^{5}$ & 0 & 20 & 40 & 60 \\
\hline \multicolumn{5}{|l|}{ Chemical composition } \\
\hline $\mathrm{DM}(\mathrm{g} / \mathrm{kg}$ fresh) & 640 & 646 & 653 & 661 \\
\hline $\mathrm{OM}$ & 925 & 923 & 922 & 922 \\
\hline $\mathrm{CP}$ & 175 & 171 & 168 & 165 \\
\hline NDF & 315 & 309 & 303 & 297 \\
\hline $\mathrm{ADF}$ & 142 & 139 & 136 & 134 \\
\hline Starch & 235 & 230 & 226 & 221 \\
\hline Water soluble carbohydrates & 31 & 30 & 30 & 29 \\
\hline $\mathrm{ME}(\mathrm{MJ} / \mathrm{kg} \text { of DM })^{6}$ & 11.8 & 12.2 & 12.7 & 13.1 \\
\hline \multicolumn{5}{|l|}{ FA } \\
\hline $16: 0$ & 3.2 & 4.6 & 6.0 & 7.4 \\
\hline 18:0 & 0.45 & 0.77 & 1.10 & 1.42 \\
\hline $18: 1$ cis-9 & 4.0 & 15.0 & 26.0 & 37.0 \\
\hline $18: 2 \mathrm{n}-6$ & 11.1 & 12.6 & 14.0 & 15.4 \\
\hline $18: 3 n-3$ & 1.7 & 1.7 & 1.6 & 1.6 \\
\hline Total FA & 22.9 & 37.7 & 52.5 & 67.3 \\
\hline
\end{tabular}

${ }^{1}$ Where CS2, CS4, and CS6 are diets containing 20,40, and $60 \mathrm{~g} / \mathrm{kg}$ of DM calcium salt of cis-monounsaturated FA, respectively.

${ }^{2}$ Pioner Rocksalt, Broste Ltd., Norfolk, UK.

${ }^{3}$ Dairy Direct, Bury St. Edmunds, Suffolk, UK.

${ }^{4}$ Sopralin, Trouw Nutrition, Belfast, UK.

${ }^{5}$ Oil content of $763 \mathrm{~g} / \mathrm{kg}$ DM, comprising $72.6 \%$ cis-9 18:1, 10.9\% 18:2n-6, $9.7 \%$ 16:0, $2.0 \% 12: 0,2.2 \% 18: 0$, as well as minor $(<1.0 \%)$ amounts of 10:0, 14:0, 20:0, cis-11 18:1, and cis-11 20:1.

${ }^{6}$ Calculated using ME reference value for the Ca-salt cis-MUFA supplement of $33.25 \mathrm{MJ} / \mathrm{kg}$ of DM.

The distribution of conjugated linoleic acid (CLA) isomers in milk FAME was determined by HPLC using 4 silver impregnated silica columns (Chromspher 5 Lipids, $250 \times 4.6 \mathrm{~mm} ; 5 \mu \mathrm{m}$ particle size; Varian, Oxford, UK) coupled in series using $0.1 \%$ ( $\mathrm{vol} / \mathrm{vol}$ ) of acetonitrile in heptanes as the mobile phase (Shingfield et al., 2003). Isomers were identified using an authentic CLA methyl ester standard (O-5632, Sigma-Aldrich, YA-Kemia Limited, Helsinki, Finland) and chemically synthesized trans-9, cis-11 CLA (Shingfield et al., 2005). Identification was verified using cis-9,trans-11 CLA as a landmark isomer.

Milk FA composition was expressed as a weight percentage of total FA using response factors derived from the analysis of a butter oil reference standard (CRM 164; Community Bureau of Reference, Brussels, Belgium). Concentrations of specific conjugated isomers in milk fat were calculated based on propor- tionate peak area responses determined by HPLC and the sum of trans-7,cis-9 CLA, trans-8,cis-10 CLA, and cis-9,trans-11 CLA weight percentage determined as a single peak by gas chromatography.

\section{Statistical Analysis}

Intake, milk production, and milk FA composition data were averaged for each cow and the means $(\mathrm{n}=$ 16) analyzed using the mixed procedure of SAS (version 8.2, SAS Institute Inc., Cary, NC) and a model testing fixed effects of treatment and period and random effects of cow, with period as a repeated effect within cow. Compound symmetry, heterogeneous compound symmetry, first-order autoregressive, heterogeneous first-order autoregressive, or an unstructured covariance structure was used for repeated measures analysis, based on goodness of fit criteria for each variable ana- 
Table 2. Effect of calcium salts of cis-monounsaturated fatty acids (Ca-MUFA) supplementation on DM and FA intake and milk and constituent yield (LSM results)

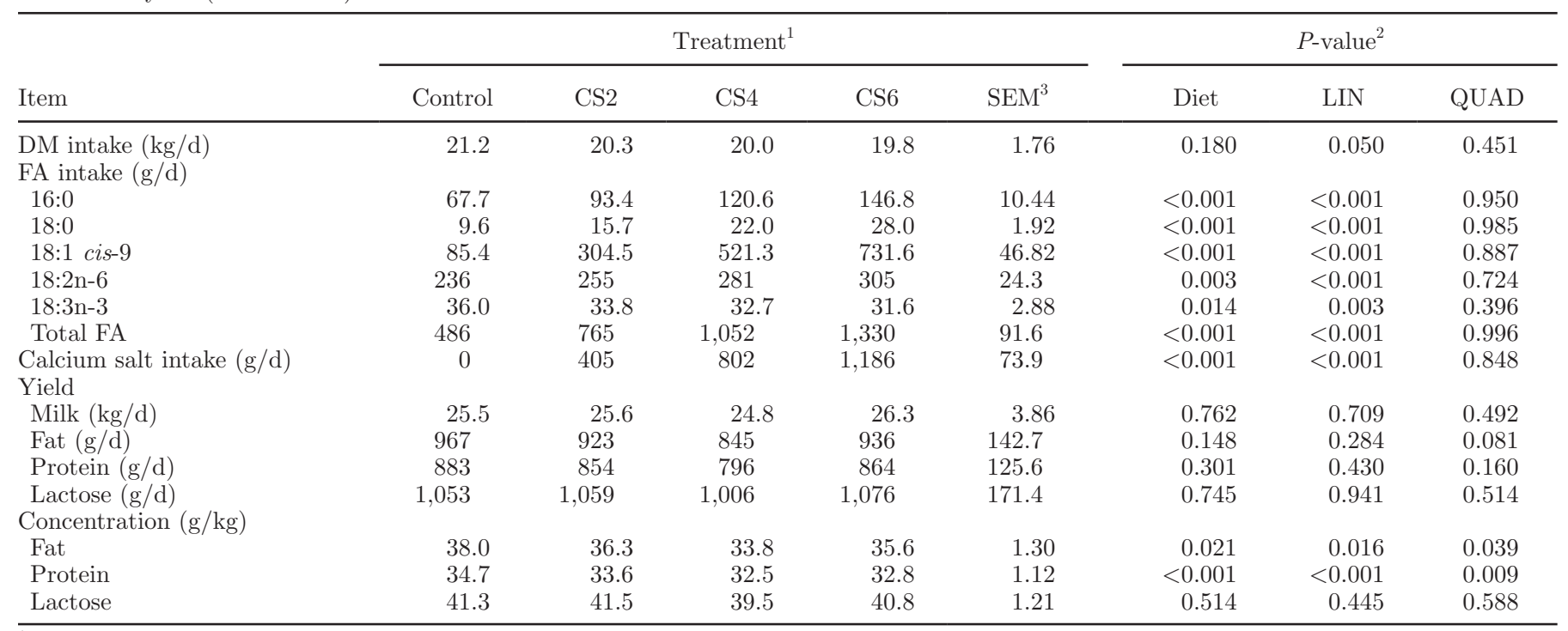

${ }^{1}$ Where CS2, CS4, and CS6 are diets containing 20, 40, and $60 \mathrm{~g} / \mathrm{kg}$ of DM Ca-MUFA, respectively.

${ }^{2}$ Refers to the significance of overall effect of diet or linear (LIN) and quadratic (QUAD) effects of increasing supplement inclusion.

${ }^{3} \mathrm{SEM}$ for $\mathrm{n}=16$ measurements.

lyzed. Orthogonal contrasts were used to test for linear, quadratic and cubic effects of Ca-MUFA inclusion level. In addition, treatment means were compared with the control mean using Dunnett's adjusted probability of difference comparisons in the LSMeans option of the Mixed procedure. Differences were deemed significant when $P<0.05$.

\section{RESULTS}

Diets were formulated so that the Ca-MUFA supplement diluted the other ingredients. This meant that $\mathrm{CP}, \mathrm{NDF}, \mathrm{ADF}$, starch, and water-soluble carbohydrate concentrations of the TMR rations decreased with increasing inclusion level of supplement (Table 1). However, this also led to successive increases in overall calculated ME content of the diets with increasing inclusion of Ca-MUFA.

For all variables, no cubic effects $(P>0.05)$ of incremental inclusion of Ca-MUFA in the diet were noted, so significance levels have not been reported. Increasing the inclusion level of Ca-MUFA supplement resulted in a linear $(P=0.05)$ reduction in DMI (Table 2). Increasing Ca-MUFA inclusion also linearly $(P<0.01)$ increased the intake of 16:0, 18:0, cis-9 18:1, 18:2 n-6, and total FA, but decreased $(P=0.003) 18: 3 \mathrm{n}-3$ intake in a linear manner. Daily ME intake was also calculated, but no significant effect of diet on $\mathrm{ME}$ intake was observed (LSM of 250, 248, 254, and $259 \mathrm{MJ} / \mathrm{d}$ for control, CS2, CS4, and CS6, respectively; $P=0.546$ ).
Milk yield and milk constituent yields were not affected by Ca-MUFA supplementation. Milk fat and protein concentrations were linearly reduced $(P=0.016$ and $P$ $<0.001$, respectively) when the Ca-MUFA supplement was fed, but the incremental effect on both milk fat and protein concentration was less for the highest dose (quadratic effects, $P=0.039$ and $P=0.009$, respectively).

Increasing the inclusion level of Ca-MUFA in the diet linearly reduced $(P<0.01)$ all short- and medium-chain SFA concentration in milk fat, apart from 4:0 (Table 3 ). Supplementation with Ca-MUFA also linearly decreased $(P<0.01)$ some branched-chain SFA $(13: 0$ anteiso, 14:0 iso, 15:0 anteiso) concentrations. Milk fat concentration of 16:0 was linearly and quadratically reduced $(P<0.01)$ with increasing Ca-MUFA supplementation. Effects on some 16:1 FA were noted, with the Ca-MUFA diets resulting in linear enhancements in trans-6/7 16:1, trans-8 16:1, trans-12 16:1, and trans-13 16:1 concentrations, and linear reductions in cis-13 16:1 concentrations. Because cis-9 16:1 co-eluted with 17:0 anteiso and trans-9 16:1 with 17:0 iso, no clear conclusions can be drawn as to which of these individual FA changed in concentration when their respective sums were linearly reduced $(P<0.001)$ by Ca-MUFA supplementation.

Supplementation of Ca-MUFA also resulted in linear increases $(P<0.02)$ in milk fat 18:0, total CLA, and total nonconjugated 18:2 isomer concentrations, and a linear decrease $(P<0.01)$ in 18:3 n-6 and 18:3 n-3 
Table 3. Effect of calcium salts of cis-monounsaturated fatty acids (Ca-MUFA) supplementation on milk FA composition (LSM results as g/100 $\mathrm{g}$ of FA)

\begin{tabular}{|c|c|c|c|c|c|c|c|c|}
\hline \multirow[b]{2}{*}{$\mathrm{FA}$} & \multicolumn{4}{|c|}{ Treatment $^{1}$} & \multirow[b]{2}{*}{$\mathrm{SEM}^{2}$} & \multicolumn{3}{|c|}{$P$-value ${ }^{3}$} \\
\hline & Control & $\mathrm{CS} 2$ & $\mathrm{CS} 4$ & CS6 & & Diet & LIN & QUAD \\
\hline $4: 0$ & 3.8 & 3.8 & 3.7 & 3.4 & 0.22 & 0.247 & 0.098 & 0.278 \\
\hline $6: 0$ & 2.7 & 2.5 & 2.3 & 2.0 & 0.13 & 0.005 & $<0.001$ & 0.448 \\
\hline $8: 0$ & 1.4 & 1.2 & 1.1 & 1.0 & 0.08 & 0.002 & $<0.001$ & 0.935 \\
\hline 10:0 & 3.2 & 2.6 & 2.20 & 1.8 & 0.21 & $<0.001$ & $<0.001$ & 0.404 \\
\hline 10:1 cis-9 & 0.36 & 0.28 & 0.22 & 0.17 & 0.029 & $<0.001$ & $<0.001$ & 0.368 \\
\hline $12: 0$ & 3.9 & 3.2 & 2.7 & 2.4 & 0.27 & $<0.001$ & $<0.001$ & 0.214 \\
\hline $12: 1$ cis-9 & 0.12 & 0.10 & 0.08 & 0.05 & 0.011 & $<0.001$ & $<0.001$ & 0.0374 \\
\hline $13: 0$ & 0.13 & 0.10 & 0.06 & 0.06 & 0.017 & $<0.001$ & $<0.001$ & 0.031 \\
\hline 13:0 anteiso & 0.10 & 0.08 & 0.07 & 0.05 & 0.010 & 0.001 & $<0.001$ & 0.458 \\
\hline $14: 0$ & 11.5 & 10.3 & 9.4 & 8.2 & 0.43 & $<0.001$ & $<0.001$ & 1.000 \\
\hline $14: 0$ iso & 0.13 & 0.11 & 0.09 & 0.08 & 0.012 & 0.005 & $<0.001$ & 0.944 \\
\hline $14: 1$ trans-9 & 0.25 & 0.21 & 0.16 & 0.13 & 0.007 & $<0.001$ & $<0.001$ & 0.671 \\
\hline $14: 1$ cis-9 & 1.32 & 1.18 & 1.02 & 0.83 & 0.085 & $<0.001$ & $<0.001$ & 0.407 \\
\hline $15: 0$ & 1.02 & 0.84 & 0.77 & 0.64 & 0.077 & $<0.001$ & $<0.001$ & 0.158 \\
\hline 15:0 anteiso & 0.46 & 0.42 & 0.37 & 0.31 & 0.016 & $<0.001$ & $<0.001$ & 0.159 \\
\hline $15: 1$ trans -5 & 0.034 & 0.038 & 0.041 & 0.034 & 0.0054 & 0.481 & 0.807 & 0.163 \\
\hline $16: 0$ & 32.3 & 26.7 & 23.4 & 20.9 & 1.34 & $<0.001$ & $<0.001$ & 0.002 \\
\hline $16: 0$ iso & 0.30 & 0.29 & 0.26 & 0.26 & 0.022 & 0.069 & 0.016 & 0.470 \\
\hline $16: 1$ trans $-6+7$ & 0.049 & 0.061 & 0.099 & 0.081 & 0.0028 & $<0.001$ & $<0.001$ & 0.001 \\
\hline 16:1 trans -8 & 0.04 & 0.07 & 0.15 & 0.14 & 0.011 & $<0.001$ & $<0.001$ & 0.006 \\
\hline $16: 1$ trans $-9^{4}$ & 0.31 & 0.30 & 0.27 & 0.26 & 0.031 & 0.001 & $<0.001$ & 0.645 \\
\hline $16: 1$ trans -10 & 0.027 & 0.022 & 0.019 & 0.024 & 0.0061 & 0.543 & 0.480 & 0.257 \\
\hline 16:1 trans-11 & 0.010 & 0.016 & 0.020 & 0.011 & 0.0049 & 0.020 & 0.156 & 0.005 \\
\hline 16:1 trans-12 & 0.134 & 0.147 & 0.166 & 0.185 & 0.0168 & 0.022 & 0.004 & 0.768 \\
\hline 16:1 trans-13 & 0.002 & 0.012 & 0.005 & 0.019 & 0.0033 & $<0.001$ & $<0.001$ & 0.068 \\
\hline $16: 1$ cis $-9^{5}$ & 2.1 & 1.8 & 1.7 & 1.4 & 0.15 & $<0.001$ & $<0.001$ & 0.765 \\
\hline $16: 1$ cis- 13 & 0.16 & 0.11 & 0.08 & 0.05 & 0.024 & $<0.001$ & $<0.001$ & 0.056 \\
\hline $3,7,11,15$ tetramethyl $16: 0$ & 0.052 & 0.063 & 0.056 & 0.041 & 0.002 & $<0.001$ & $<0.001$ & $<0.001$ \\
\hline $17: 0$ & 0.46 & 0.40 & 0.33 & 0.28 & 0.016 & $<0.001$ & $<0.001$ & 0.640 \\
\hline $17: 1$ cis-7 & 0.17 & 0.14 & 0.11 & 0.09 & 0.010 & $<0.001$ & $<0.001$ & 0.582 \\
\hline $18: 0$ & 7.8 & 9.0 & 9.3 & 9.4 & 0.65 & 0.052 & 0.017 & 0.135 \\
\hline 18:1 trans total & 3.4 & 5.4 & 7.9 & 9.6 & 0.14 & $<0.001$ & $<0.001$ & 0.119 \\
\hline $18: 1$ cis total & 16.5 & 21.5 & 25.2 & 28.8 & 1.01 & $<0.001$ & $<0.001$ & 0.095 \\
\hline Non-CLA 18:2 total ${ }^{6}$ & 2.9 & 3.0 & 3.1 & 3.3 & 0.20 & 0.028 & 0.006 & 0.405 \\
\hline CLA total & 0.77 & 1.29 & 1.60 & 1.84 & 0.095 & $<0.001$ & $<0.001$ & 0.006 \\
\hline $18: 3 n-6$ & 0.033 & 0.024 & 0.020 & 0.018 & 0.0020 & 0.004 & $<0.001$ & 0.067 \\
\hline $18: 3 n-3$ & 0.225 & 0.215 & 0.165 & 0.189 & 0.0190 & 0.010 & 0.006 & 0.101 \\
\hline $19: 0^{7}$ & 0.042 & 0.051 & 0.057 & 0.058 & 0.0020 & 0.001 & $<0.001$ & 0.050 \\
\hline 20:0 & 0.103 & 0.105 & 0.106 & 0.098 & 0.0093 & 0.532 & 0.401 & 0.284 \\
\hline $20: 1$ cis-9 & 0.075 & 0.076 & 0.072 & 0.065 & 0.0044 & 0.036 & 0.011 & 0.140 \\
\hline $20: 1$ cis-11 & 0.027 & 0.035 & 0.053 & 0.085 & 0.0102 & 0.021 & 0.004 & 0.247 \\
\hline $20: 2 n-6$ & 0.040 & 0.038 & 0.033 & 0.022 & 0.0046 & 0.126 & 0.033 & 0.367 \\
\hline $20: 3 n-6$ & 0.139 & 0.115 & 0.106 & 0.088 & 0.0116 & $<0.001$ & $<0.001$ & 0.089 \\
\hline $20: 4 n-6$ & 0.136 & 0.110 & 0.100 & 0.078 & 0.0049 & $<0.001$ & $<0.001$ & 0.590 \\
\hline $22: 0$ & 0.035 & 0.033 & 0.027 & 0.026 & 0.0043 & 0.009 & 0.002 & 0.414 \\
\hline $22: 4 n-6$ & 0.020 & 0.020 & 0.021 & 0.014 & 0.0018 & 0.042 & 0.157 & 0.143 \\
\hline $22: 5 n-3$ & 0.040 & 0.032 & 0.028 & 0.023 & 0.0041 & 0.023 & 0.004 & 0.662 \\
\hline $24: 0$ & 0.020 & 0.017 & 0.005 & 0.002 & 0.0023 & 0.001 & $<0.001$ & 1.000 \\
\hline$\Sigma \mathrm{SFA}$ & 71.0 & 63.1 & 57.1 & 51.6 & 1.66 & $<0.001$ & $<0.001$ & 0.008 \\
\hline$\Sigma \mathrm{SFA} \leq 14: 0$ & 27.2 & 24.1 & 21.5 & 18.8 & 1.05 & $<0.001$ & $<0.001$ & 0.738 \\
\hline$\Sigma$ trans total & 6.1 & 9.6 & 12.9 & 15.6 & 0.74 & $<0.001$ & $<0.001$ & $<0.001$ \\
\hline$\Sigma$ trans MUFA & 4.3 & 6.2 & 8.7 & 10.5 & 0.22 & $<0.001$ & $<0.001$ & 0.691 \\
\hline$\Sigma$ cis $\mathrm{MUFA}$ & 19.9 & 24.4 & 26.7 & 30.8 & 0.91 & $<0.001$ & $<0.001$ & 0.073 \\
\hline$\Sigma$ n-6 PUFA & 3.1 & 3.0 & 3.1 & 3.2 & 0.20 & 0.048 & 0.033 & 0.050 \\
\hline$\Sigma$ n-3 PUFA & 0.40 & 0.41 & 0.42 & 0.38 & 0.013 & 0.001 & 0.054 & $<0.001$ \\
\hline n-6:n-3 & 7.3 & 7.1 & 8.1 & 8.2 & 0.43 & 0.028 & 0.010 & 0.500 \\
\hline
\end{tabular}

${ }^{1}$ Where CS2, CS4, and CS6 are diets containing 20, 40, and $60 \mathrm{~g} / \mathrm{kg}$ of DM Ca-MUFA, respectively.

${ }^{2} \mathrm{SEM}$ for $\mathrm{n}=16$ measurements.

${ }^{3}$ Refers to the significance of overall effect of diet or linear (LIN) and quadratic (QUAD) effects of increasing supplement inclusion.

${ }^{4}$ Co-elutes with 17:0 iso.

${ }^{5}$ Co-elutes with 17:0 anteiso.

${ }^{6} \mathrm{CLA}=$ conjugated linoleic acid. All 18:2 isomers excluding CLA.

${ }^{7}$ Co-elutes with cis-15 18:1. 
concentrations (Table 3). Effects of Ca-MUFA supplementation on some of the longer chain FA present in milk at low concentrations were also noted. Overall, increasing inclusion of Ca-MUFA caused a linear and quadratic reduction $(P<0.001)$ in total SFA, and a linear reduction $(P<0.001)$ in SFA $<14: 0$ (Table $3)$. Total trans- and cis-MUFA linearly increased $(P$ $<0.001$ ) with increasing Ca-MUFA supplementation. Overall, a slight increase $(P=0.033)$ in total n-6 PUFA and a decrease $(P=0.001)$ in total n-3 PUFA was observed, so that the n-6:n-3 ratio increased linearly $(P$ $<0.05)$ with increasing Ca-MUFA inclusion level.

Increasing the inclusion level of Ca-MUFA in the dairy cow diet resulted in linear increases $(P<0.01)$ in all 18:1 trans isomers measured, and also 18:1 cis9, 18:1 cis-11, and 18:1 cis-13 $(P<0.001$; Table 4$)$. Quadratic responses $(P<0.05)$ were also noted for trans-5 18:1, trans-9 18:1, trans-10 18:1, trans-12 18:1, trans-13/14 18:1, and trans-16/cis-14 18:1 (the latter isomers co-eluted). This resulted in an overall linear enhancements $(P<0.001)$ in total trans-18:1 and total cis-18:1 (Table 3). Supplementation with Ca-MUFA caused variable responses in 18:2 isomers (Table 5). Linear increases $(P<0.01)$ were observed in trans-9, cis-12 18:2, and trans-11,cis-15 18:2, and a linear and quadratic enhancement in cis-9,trans-12 18:2 and cis9,cis-12 18:2 concentrations with increasing supplement inclusion level. However, increasing Ca-MUFA inclusion caused a linear and quadratic reduction $(P<0.01)$ in trans-11,trans-15 and cis-10,trans-14 18:2.

With regard to CLA isomer composition, linear and in some cases quadratic increases $(P<0.01)$ were noted in the concentrations of several isomers (trans-11,trans-13 CLA; trans-10,trans-12 CLA; trans-9,trans-11 CLA; trans-8,trans-10 CLA; trans-7,trans-9 CLA; trans10,cis-12 CLA; trans-8, cis-10 CLA; trans-7,cis-9 CLA; and cis-9,trans-11 CLA; Table 5).

\section{DISCUSSION}

Feeding cis-MUFA-rich lipid sources to dairy cows is an effective strategy to reduce milk fat SFA and increase cis-MUFA concentrations. However, this is also commonly associated with increases in trans fatty acid (TFA) concentrations via rumen biohydrogenation of cis-MUFA and PUFA present in the oil (Chilliard et al., 2007 ). One of the issues associated with creating calcium salts of unsaturated FA (particularly highly unsaturated FA) to protect against this rumen metabolism is apparent dissociation. In vitro studies have reported that the greater the unsaturation of a calcium salt, the greater the risk of dissociation. Sukhija and Palmquist (1990) found that across a range of $\mathrm{pH}$ values, calcium salts of soybean oil (containing proportionately less cis-9 18:1 and more 18:2 n-6) dissociates more readily than calcium salts of oils containing more cis-9 18:1 and less PUFA. A later study, by Van Nevel and Demeyer (1996), reported that between $\mathrm{pH}$ of 6.9 and 6.3 , calcium salts of PUFA are partially protected against biohydrogenation; but protection varies with degree of unsaturation, with 18:2 n- 6 calcium salts protected to a greater extent than 18:3 n-3 calcium salts. These studies suggest that calcium salts of predominantly cis-9 18:1 are probably better protected than calcium salts of

Table 4. Effect of calcium salts of cis-monounsaturated fatty acids (Ca-MUFA) supplementation on milk fat 18:1 isomer composition (LSM results as $\mathrm{g} / 100 \mathrm{~g}$ of $\mathrm{FA}$ )

\begin{tabular}{|c|c|c|c|c|c|c|c|c|}
\hline FA & \multicolumn{4}{|c|}{ Treatment $^{1}$} & $\mathrm{SEM}^{2}$ & \multicolumn{3}{|c|}{$P$-value ${ }^{3}$} \\
\hline trans-4 18:1 & 0.013 & 0.037 & 0.073 & 0.116 & 0.0145 & $<0.001$ & $<0.001$ & 0.073 \\
\hline trans-6-8 $18: 1$ & 0.23 & 0.58 & 1.01 & 1.33 & 0.078 & $<0.001$ & $<0.001$ & 0.197 \\
\hline trans-9 18:1 & 0.22 & 0.52 & 0.78 & 0.96 & 0.060 & $<0.001$ & $<0.001$ & 0.006 \\
\hline trans-10 18:1 & 0.37 & 0.76 & 0.88 & 1.09 & 0.075 & $<0.001$ & $<0.001$ & 0.033 \\
\hline trans-16 18:1/cis-14 18:1 & 0.24 & 0.29 & 0.31 & 0.30 & 0.028 & 0.009 & 0.004 & 0.022 \\
\hline cis-9 18:1 & 15.4 & 20.2 & 23.8 & 27.2 & 0.94 & $<0.001$ & $<0.001$ & 0.109 \\
\hline cis-11 18:1 & 0.49 & 0.58 & 0.68 & 0.76 & 0.041 & $<0.001$ & $<0.001$ & 0.481 \\
\hline cis-12 18:1 & 0.36 & 0.36 & 0.34 & 0.33 & 0.035 & 0.134 & 0.036 & 0.900 \\
\hline cis-13 18:1 & 0.076 & 0.123 & 0.157 & 0.189 & 0.0078 & $<0.001$ & $<0.001$ & 0.090 \\
\hline cis-15 18:1 & 0.042 & 0.051 & 0.057 & 0.058 & 0.0020 & 0.014 & $<0.001$ & 0.050 \\
\hline
\end{tabular}

${ }^{1}$ Where CS2, CS4, and CS6 are diets containing 20, 40, and $60 \mathrm{~g} / \mathrm{kg}$ of DM Ca-MUFA, respectively.

${ }^{2} \mathrm{SEM}$ for $\mathrm{n}=16$ measurements.

${ }^{3}$ Refers to the significance of overall effect of diet or linear (LIN) and quadratic (QUAD) effects of increasing supplement inclusion. 
Table 5. Effect of calcium salts of cis-monounsaturated fatty acids (Ca-MUFA) supplementation on milk fat 18:2 isomer composition (LSM results as $\mathrm{mg} / 100 \mathrm{~g}$ of $\mathrm{FA}$ )

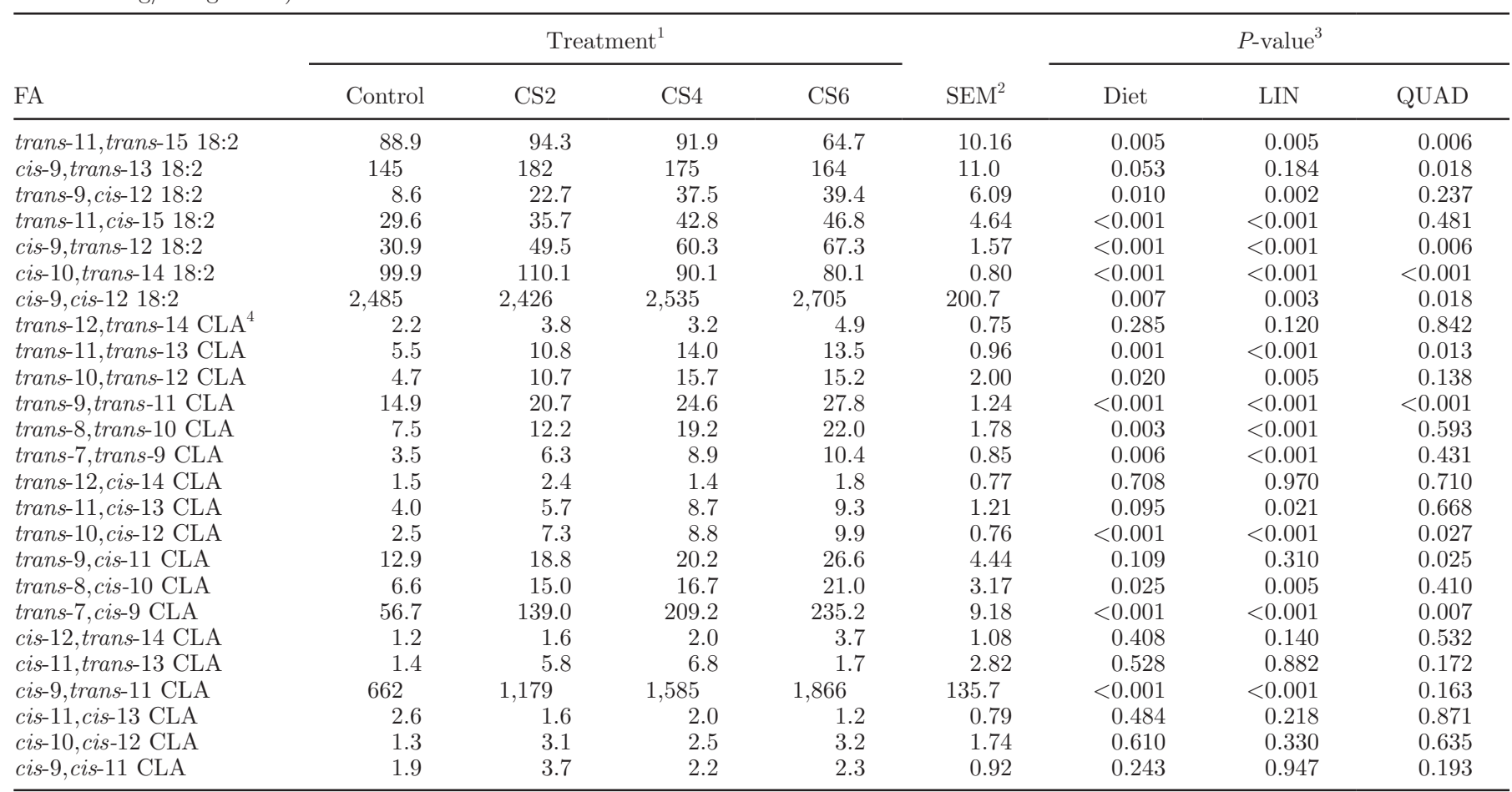

${ }^{1}$ Where CS2, CS4, and CS6 are diets containing 20, 40, and $60 \mathrm{~g} / \mathrm{kg}$ DM calcium salt, respectively.

${ }^{2} \mathrm{SEM}$ for $\mathrm{n}=16$ measurements.

${ }^{3}$ Refers to the significance of overall effect of diet or linear (LIN) and quadratic (QUAD) effects of increasing supplement inclusion.

${ }^{4} \mathrm{CLA}=$ conjugated linoleic acid.

PUFA. Apart from degree of unsaturation, particle size is thought to affect dissociation of calcium salt supplements. Block et al. (2008) reported a higher rate of increase in rumen concentration of 18:0 when smaller particles of a calcium salt supplement were incubated in vitro compared with larger particles of the same supplement.

The FA profile of the Ca-MUFA supplement in the present study was different to that of rapeseed oil (Glasser et al., 2008), with a higher cis-9 18:1 content, around half the 18:2 n- 6 content, and much less 18:3 n-3. In fact, the Ca-MUFA profile was similar to that of high oleic acid (low PUFA) rapeseed types, which have been used in dairy cow diets to try to reduce milk fat PUFA concentrations and thereby address product shelf-life issues (Jenkins, 1998; Loor et al., 2002). It was anticipated that the high oleic acid content of the CaMUFA, when rumen-protected, would increase transfer of cis-9 18:1 from the diet to milk fat by minimizing dissociation and exposure to rumen microorganisms.

Increasing inclusion of Ca-MUFA resulted in a linear reduction in DMI. Lin et al. (1996) reported a lack of DMI response when feeding incremental amounts (25 and $49 \mathrm{~g} / \mathrm{kg}$ of DM) of calcium salts of a high oleic acid sunflower oil, and Chouinard et al. (1998) reported no significant differences in DMI between a control diet and diets containing calcium salts of different lipid sources $(40 \mathrm{~g} / \mathrm{kg}$ of DM). Incremental infusion of high oleic acid sunflower oil into the abomasum of dairy cows, thus bypassing the effects of the rumen, was reported to decrease DMI (Drackley et al., 2007), with the authors concluding that monounsaturated free FA decrease DMI in a dose-dependent manner. This, together with the fact that in the present study increasing Ca-MUFA supplementation had no effect on ME intake, suggests that the DMI was suppressed due to both increasing energy density of the diet and also a greater proportion of unsaturated FA leaving the rumen.

Supplementation with Ca-MUFA had no effect on milk yield, which may reflect the consistent calculated ME intake across inclusion levels or stage of lactation. A similar result was reported by Lin et al. (1996) and Chouinard et al. (1998) following supplementation with calcium salts of oleic acid-rich oils. In the current study, energy density of the diet was increased by including Ca-MUFA at the expense of the other nutrients required for milk production, which may have masked any increases in production. Furthermore, the use of 
mid- to late-lactation cows may also explain the lack of a response after Kirkland and Gordon (2001) demonstrated that cows in later lactation (411-428 DIM) partitioned less of their dietary increase in ME intake toward milk energy output than cows in early lactation.

No effect of diet on milk fat, protein, and lactose yield was observed, although milk fat and protein concentrations were reduced, and the responses were less at the higher inclusion levels. Studies have shown that including unsaturated oil supplements in dairy cow diets can suppress both fat and protein concentration in milk (Kliem, 2010), partially due to the negative effects of unsaturated oils on the rumen environment, and also due to increases in milk yield with no accompanying change in fat and protein production. In the present study, no change in milk yield was noted with increasing supplement inclusion level, which may explain the lack of effect on milk component yield. Milk fat suppression is also related to increased rumen outflow of specific unsaturated FA, which can inhibit milk fat synthesis (Chilliard et al., 2007). However duodenal infusion of oleic acid has been shown to have little effect on milk fat concentration (Enjalbert et al., 1997). In the current study, the increase in trans-10, cis-12 CLA reaching the mammary gland (reflected in increased milk concentration) may have had some effect on milk fat synthesis. In addition, the supplement diluted other dietary ingredients, leading to a reduction in fermentable energy and $\mathrm{CP}$ intake, which may have been the cause of lower milk protein concentration.

The effect of Ca-MUFA supplementation on shortand medium-chain SFA concentration in milk fat may be in part due to a concentration effect, reflecting the increase in concentration observed in longer chain unsaturated FA. However, a more likely explanation is the inhibition of mammary de novo synthesis by long-chain unsaturated FA which have either escaped rumen biohydrogenation or are intermediates of this process. Indeed, when taking total daily milk fat yield into account, we observed linear $(P<0.001)$ decreases in the daily output of the sum of de novo-synthesized FA 4:0 to 14:0 (300 and $190 \mathrm{~g} / \mathrm{d}$ for control and CS6, respectively) and 16:0 (237 and $165 \mathrm{~g} / \mathrm{d}$ for control and CS6, respectively). Increasing the amount of long chain ( $\geq 18$-carbon) unsaturated FA in the diet has been found to inhibit de novo synthesis (Barber et al., 1997; Chilliard et al., 2000). Studies have shown that calcium salts of unsaturated FA do reduce milk fat concentrations of SFA synthesized de novo (Chouinard et al., 1998; Harvatine and Allen, 2006). As well as short- and mediumchain SFA, calcium salt supplements also reduced the milk fat concentration of odd- and branched-chain SFA (such as 13:0 anteiso, 15:0); again, this may have been a concentration effect. However, most of these FA in milk are known to be mainly synthesized de novo by rumen bacteria (Vlaeminck et al., 2006), suggesting that Ca-MUFA inclusion may have had some effect on the rumen environment.

The concentration of 16:0 was reduced by almost 12 $\mathrm{g} / 100 \mathrm{~g}$ of FA. Mammary de novo synthesis accounts for about $50 \%$ of $16: 0$ in milk fat (Hawke and Taylor, 1995) with the remainder being supplied by the circulation. The Ca-MUFA supplement contained around 11 $\mathrm{g} / 100 \mathrm{~g}$ of FA 16:0, and intake of this FA did increase. Therefore, the reduction in milk fat 16:0 concentration is probably related to inhibition of de novo synthesis, which was reflected in the linear reduction in daily output already mentioned. In contrast, milk fat 18:0 concentration was enhanced with increasing inclusion of Ca-MUFA supplement. Concentration of 18:0 in milk fat is usually enhanced following supplementation of dairy cow diets with 18-carbon PUFA-rich oilseed supplements (Givens and Shingfield, 2006), complete rumen biohydrogenation of which leads to increased availability of 18:0 for absorption by the small intestine. In addition, a high proportion of unprotected cis-9 18:1 is metabolized to 18:0 in the rumen (Harfoot and Hazlewood, 1997; Jenkins et al., 2008). In the current study, increased concentration of 18:0 in milk may have been due to increased intake, or perhaps cis-9 18:1 and 18:2 n-6 within the supplement were subjected to limited rumen biohydrogenation, but the increase was small when compared with earlier studies and no overall diet effect on milk output $(\mathrm{g} / \mathrm{d})$ of 18:0 $(P=0.104)$ was noted. A greater increase in milk fat 18:0 concentration was observed by Chouinard et al. (1998) after supplementing cow diets with calcium salts of rapeseed oil. A study comparing supplementary soybean oil with a calcium salt of soybean oil reported no difference in omasal flow of 18:0 (Lundy et al., 2004); however, both these previous studies suggest rumen protection was not complete for the calcium salt supplements used. Despite marginal increases in 18:0 concentration, CaMUFA supplementation reduced total SFA by almost $20 \mathrm{~g} / 100 \mathrm{~g}$ of FA at the highest inclusion level $(60 \mathrm{~g} / \mathrm{kg}$ of DM). Supplementation with $33 \mathrm{~g} / \mathrm{kg}$ of DM calcium salts of unsaturated FA reduced total (6:0-20:0) SFA from 62 to $54 \mathrm{~g} / 100 \mathrm{~g}$ of $\mathrm{FA}$ (Harvatine and Allen, 2006).

The reduction in total SFA concentration with increasing Ca-MUFA inclusion was balanced by an enhancement in concentration of total cis- and trans-18:1, total CLA, and total nonconjugated 18:2 in the present study. The proportion of cis-9 18:1 in milk fat increased with increasing inclusion of Ca-MUFA supplement. This FA is derived from dietary sources, but also from desaturation of 18:0 by mammary $\Delta^{9}$-desaturase. One in vivo study estimated that $\Delta^{9}$-desaturase was respon- 
sible for $59 \%$ cis-9 18:1 present in milk fat (Mosley and McGuire, 2007). Supplementation with Ca-MUFA also increased the concentration of minor cis-18:1 isomers (cis-11 18:1 and cis-13 18:1), which are probably biohydrogenation intermediates of dietary PUFA. Concentration of cis-13 18:1 was enhanced during in vitro incubation of 18:2 n- 6 with rumen bacteria (Jouany et al., 2007), and rumen fluid concentration of cis-11 18:1 and cis-13 18:1 was higher in cows supplemented with canola or soybean oil than in cows fed a control diet (Loor et al., 2002).

Supplement inclusion increased all trans-18:1 isomers measured, which are intermediates of rumen biohydrogenation of PUFA and MUFA. In vitro and in vivo studies have established that trans-11 18:1, usually the most abundant trans-18:1 in milk fat, is a common intermediate of 18:2 n-6 and 18:3 n-3 metabolism in the rumen (Harfoot and Hazlewood, 1997; Palmquist et al., 2005). In vitro studies have also demonstrated that cis-9 18:1 is converted to a range of trans-18:1 isomers during incubation with rumen-derived microorganisms including trans-7, trans-9, trans-10, and trans-12 18:1 (Mosley et al., 2002; McKain et al., 2010). Almost all trans-9 18:1 produced during $24 \mathrm{~h}$ of in vitro incubation derived from cis-9 18:1 (Mosley et al., 2002). In addition, trans-9 18:1 has been shown to further isomerize during in vitro incubation with rumen bacteria to a range of positional trans 18:1 isomers (Proell et al., 2002). Furthermore, it is thought that altered rumen fermentation with certain diets results in a shift in biohydrogenation pathway for 18:2 n-6, leading to accumulation of trans-10 18:1 (Bauman and Griinari, 2001). The intermediate in this pathway (trans-10,cis-12 CLA) is thought to be involved in milk fat depression, and abomasal infusion of this isomer has resulted in significant reductions in milk fat concentration (Baumgard et al., 2000; Lock et al., 2007). An increased concentration was observed in this isomer together with several other CLA isomers, such as trans-7,cis-9 and cis-9,trans-11 CLA. The increases in these latter isomers suggest increased availability of trans-7 $18: 1$ and trans-11 18:1 at the mammary gland, and subsequent mammary desaturation (Piperova et al., 2002). In vitro incubation of 18:2 n- 6 has also been found to enhance concentrations of trans-8,trans-10 CLA and trans-9,trans-11 CLA (Jouany et al., 2007). These CLA isomers were enhanced in milk in the current study with increasing supplement inclusion (consistent with overall dietary 18:2 n-6 content), providing further evidence of some rumen exposure to the supplement FA.

The increase in nonconjugated 18:2 isomers with CaMUFA inclusion also reflects increased rumen exposure to $18: 2 \mathrm{n}-6$. Concentrations of trans-9,cis-12 18:2 and cis-9,trans-12 18:2 were found to be greater during in vitro incubation of 18:2 n- 6 with rumen fluid (Jouany et al., 2007), and studies have shown supplementing dairy cows with oils rich in 18:2 n-6 enhances rumen cis-9,trans-12 concentration (Loor et al., 2002).

Replacing SFA with cis-MUFA in milk fat offers a successful means of improving the health quality of milk. A modeling exercise demonstrated that if milk fat SFA and cis-MUFA content was altered from 70 and 20 $\mathrm{g} / 100 \mathrm{~g}$ of FA to 55 and $32 \mathrm{~g} / 100 \mathrm{~g}$ of FA, respectively, this would result in a mean reduction in risk of coronary heart disease event in $11 \mathrm{EU}$ member states by almost 2\% (UK reduction in risk of $1.67 \%$; Givens, 2008). Considering the cost of CVD in the EU through direct and indirect healthcare costs, a reduction in risk of this magnitude is substantial. However, this model did not consider the negative effects of any TFA that may be enhanced in milk fat following manipulation of milk FA profile. At current intake levels, ruminant-derived TFA are thought not to have negative effects on human health (Mozaffarian et al., 2006), and as such, are not included in public health drives to reduce trans fat intake (Faculty of Public Health, 2010). In addition, the different isomer profile of ruminant-derived compared with industrial TFA may result in differing responses in certain CVD risk factors (Motard-Bélanger et al., 2008). However, food labeling for TFA is now mandatory in the United States, Denmark, and Canada, with calls for compulsory labeling in the United Kingdom (Clarke and Lewington, 2006). Until such labels distinguish between the 2 sources of TFA, efforts should be made to keep any increase in concentration in milk and dairy products to a minimum. This could include rumen protection of dietary unsaturated FA, so research should be conducted into further development of such products.

\section{CONCLUSIONS}

The main objectives of this study were to measure the effect of feeding increasing amounts of a high-C18:1 calcium salt supplement on feed intake, milk yield or composition, and FA composition. Overall, the CaMUFA preparation used to protect unsaturated FA from rumen metabolism was not entirely successful, but the product was very effective at reducing the SFA (by $27 \%$ ) and increasing cis-MUFA (by 55\%) concentrations of milk fat. No effect on milk yield was noted, but fat and protein concentrations were both reduced, which may suggest inhibition of fat synthesis and some modification of the rumen environment, or reflect the slight changes in milk yield observed. Fat reduction (and decreased concentration of de novo-synthesized SFA) may also have been partially due to unsaturated FA from the Ca-MUFA being protected from rumen 
biohydrogenation. But evidence of biohydrogenation of unsaturated FA also exists, in that milk 18:0, trans-18:1, CLA, and nonconjugated 18:2 were all enriched in milk fat from cows fed diets supplemented with increasing amounts of Ca-MUFA. This indicates that some of the unsaturated FA in the Ca-MUFA supplement were exposed to rumen microorganisms.

\section{ACKNOWLEDGMENTS}

This study was funded jointly by the Biotechnology and Biological Sciences Research Council (BBSRC) Diet and Health Research Industry Club (DRINC) Project (BB/1006087/1) and Volac International Ltd. (Royston, UK). The authors acknowledge the European Union European Co-operation in Science and Technology (EU-COST) Action No. FA0802 Feed for Health, which funded a training short term scientific mission for K. Kliem and K. Livingstone at MTT AgriFood Research, Finland, for analysis of conjugated linoleic acid isomers by HPLC. They also thank Kevin Shingfield and staff at MTT for their assistance in HPLC analytical techniques. The staff at the Centre for Dairy Research, University of Reading, is gratefully acknowledged for care of the experimental animals.

\section{REFERENCES}

Ashes, J. R., P. St. Vincent Welch, S. K. Gulati, T. W. Scott, G. H. Brown, and S. Blakely. 1992. Manipulation of the fatty acid composition of milk by feeding protected canola seeds. J. Dairy Sci. 75:1090-1096.

Barber, M. C., R. A. Clegg, M. T. Travers, and R. G. Vernon. 1997. Lipid metabolism in the lactating mammary gland. Biochim. Biophys. Acta 1347:101-126.

Bates, B., A. Lennox, and G. Swann. 2010. National Diet and Nutrition Survey. Headline results from year 1 of the rolling programme (2008/2009). Food Standards Agency, London, UK.

Bauman, D. E., and J. M. Griinari. 2001. Regulation and nutritional manipulation of milk fat: Low-fat milk syndrome. Livest. Prod. Sci. 70:15-29.

Baumgard, L. H., B. A. Corl, D. A. Dwyer, A. Saebø, and D. E. Bauman. 2000. Identification of the conjugated linoleic acid isomer that inhibits milk fat synthesis. Am. J. Phys. 278:R179-R184.

Block, E., E. Evans, C. J. Sniffen, and N. Clark. 2008. Effects of particle size of calcium salts of fatty acids on rates of biohydrogenation and disappearance of essential fatty acids in sacco. J. Dairy Sci. 91(E-Suppl. 1):332. (Abstr.)

Chilliard, Y., A. Ferlay, R. J. Mansbridge, and M. Doreau. 2000. Ruminant milk fat plasticity: Nutritional control of saturated, polyunsaturated, trans and conjugated fatty acids. Ann. Zootech. 49:181-205.

Chilliard, Y., F. Glasser, A. Ferlay, L. Bernard, J. Rouel, and M. Doreau. 2007. Diet, rumen biohydrogenation and nutritional quality of cow and goat milk fat. Eur. J. Lipid Sci. Technol. 109:828855 .

Chouinard, P. Y., V. Girard, and G. J. Brisson. 1997. Lactational response of cows to different concentrations of calcium salts of canola oil fatty acids with or without bicarbonate. J. Dairy Sci. 80:1185-1193.

Chouinard, P. Y., V. Girard, and G. J. Brisson. 1998. Fatty acid profile and physical properties of milk fat from cows fed calcium salts of fatty acids with varying unsaturation. J. Dairy Sci. 81:471-481.
Clarke, R., and S. Lewington. 2006. Trans fatty acids and coronary heart disease. BMJ 333:214

Drackley, J. K., T. R. Overton, G. Ortiz-Gonzales, A. D. Beaulieu, D. M. Barbano, J. M. Lynch, and E. G. Perkins. 2007. Responses to increasing amounts of high-oleic sunflower fatty acids infused into the abomasum of lactating dairy cows. J. Dairy Sci. 90:51655175 .

Enjalbert, F., M. C. Nicot, C. Bayourthe, M. Vernay, and R. Moncoulon. 1997. Effects of dietary calcium soaps of unsaturated fatty acids on digestion, milk composition and physical properties of butter. J. Dairy Res. 64:181-195.

Faculty of Public Health. 2010. Twelve steps to better public health: A manifesto. Faculty of Public Health/Royal Society for Public Health. Accessed Feb. 27, 2013. http://www.fph.org.uk/uploads/ manifesto_public_health.pdf.

Ferlay, A., Y. Chilliard, and M. Doreau. 1992. Effects of calcium salts differing in fatty acid composition on duodenal and milk fatty acid profiles in dairy cows. J. Sci. Food Agric. 60:31-37.

Givens, D. I. 2008. Impact on CVD risk of modifying milk fat to decrease intake of SFA and increase intake of cis-MUFA. Proc. Nutr. Soc. $67: 419-427$.

Givens, I. 2009. Animal nutrition and lipids in animal products and their contribution to human intake and health. Nutrients 1:71-82.

Givens, D. I., K. E. Kliem, D. J. Humphries, K. J. Shingfield, and R. Morgan. 2009. Effect of replacing calcium salts of palm oil distillate with rapeseed oil, milled or whole rapeseeds on milk fatty acid composition in cows fed maize silage-based diets. Animal $3: 1067-1074$.

Givens, D. I., and K. J. Shingfield. 2006. Optimising dairy milk fatty acid composition. Pages 252-280 in Improving the Fat Content of Foods. C. Williams and J. Buttriss, ed. Woodhead Publishing Ltd., Cambridge, UK.

Glasser, F., A. Ferlay, and Y. Chilliard. 2008. Oilseed supplements and fatty acid composition of cow milk: A meta-analysis. J. Dairy Sci. 91:4687-4703.

Harfoot, C. G., and G. P. Hazlewood. 1997. Lipid metabolism in the rumen. Pages 382-426 in The Rumen Microbial Ecosystem. P. N. Hobson and C. S. Stewart, ed. Blackie Academic and Professional, London, UK.

Harvatine, K. J., and M. S. Allen. 2006. Effects of fatty acid supplements on milk yield and energy balance of lactating dairy cows. J. Dairy Sci. 89:1081-1091.

Hawke, T. W., and J. C. Taylor. 1995. Influence of nutritional factors on the yield, composition and physical properties of milk fat. Pages 37-88 in Advanced Dairy Chemistry Vol. 2: Lipids. P. F. Fox, ed. Chapman and Hall, London, UK.

Hulshof, K. F. A. M., M. A. van Erp-Baart, M. Anttolainen, W. Becker, S. M. Church, C. Couet, E. Hermann-Kunz, H. Kesteloot, T. Leth, I. Martins, O. Moreiras, J. Moschandreas, L. Pizzoferrato, A. H. Rimestad, H. Thorgeirsdottir, J. M. M. van Amelsvoort, A. Aro, A. G. Kafatos, D. Lanzmann-Petithory, and G. van Poppel. 1999. Intake of fatty acids in western Europe with emphasis on trans fatty acids: The TRANSFAIR study. Eur. J. Clin. Nutr. $53: 143-157$

Jenkins, T. C. 1998. Fatty acid composition of milk from Holstein cows fed oleamide or canola oil. J. Dairy Sci. 81:794-800.

Jenkins, T. C., R. J. Wallace, P. J. Moate, and E. E. Mosley. 2008. Recent advances in biohydrogenation of unsaturated fatty acids within the rumen microbial ecosystem. J. Anim. Sci. 86:397-412.

Jouany, J.-P., B. Lassalas, M. Doreau, and F. Glasser. 2007. Dynamic features of the rumen metabolism of linoleic acid, linolenic acid and linseed oil in vitro. Lipids 42:351-360.

Kirchgessner, M., H. Friesecke, and G. Koch. 1967. Nutrition and the Composition of Milk. Corsby, Lockwood and Son, London, UK.

Kirkland, R. M., and F. J. Gordon. The effects of stage of lactation on the partitioning of, and responses to changes in, metabolisable energy intake in lactating dairy cows. Livest. Prod. Sci. 72:213-224.

Kliem, K. E. 2010. Improving the health quality of milk by reducin the saturated fatty acid content using supplemental oilseeds. PhD Thesis. University of Reading, Reading, UK. 
Kliem, K. E., R. Morgan, D. J. Humphries, K. J. Shingfield, and D. I. Givens. 2008. Effect of replacing grass silage with maize silage in the diet on bovine milk fatty acid composition. Animal $2: 1850-1858$.

Lin, M.-P., C. R. Staples, C. A. Sims, and S. F. O'Keefe. 1996. Modification of fatty acids in milk by feeding calcium-protected high oleic sunflower oil. J. Food Sci. 61:24-27.

Lock, A. L., C. Tyburczy, D. A. Dwyer, K. J. Harvatine, F. Destaillats, Z. Mouloungui, and D. E. Bauman. 2007. Trans-10 octadecenoic acid does not reduce milk fat synthesis in dairy cows. J. Nutr. 137:71-76.

Loor, J. J., A. B. P. A. Bandara, and J. H. Herbein. 2002. Characterization of 18:1 and 18:2 isomers produced during microbial biohydrogenation of unsaturated fatty acids from canola and soya bean oil in the rumen of lactating cows. J. Anim. Physiol. Anim. Nutr. 86:422-432.

Lundy, F. P., E. Block, W. C. Bridges, J. A. Bertrand, and T. C. Jenkins. 2004. Ruminal biohydrogenation in Holstein cows fed soybean fatty acids as amides or calcium salts. J. Dairy Sci. 87:1038-1046.

McKain, N., K. J. Shingfield, and R. J. Wallace. 2010. Metabolism of conjugated linoleic acids and 18:1 fatty acids by ruminal bacteria: Products and mechanisms. Microbiology 156:579-588.

Mosley, E. E., and M. A. McGuire. 2007. Methodology for the in vivo measurement of the $\Delta^{9}$-desaturation of myristic, palmitic and stearic acids in lactating dairy cattle. Lipids 42:939-945.

Mosley, E. E., G. L. Powell, M. B. Riley, and T. C. Jenkins. 2002. Microbial biohydrogenation of oleic acid to trans isomers in vitro. J. Lipid Res. 43:290-296.

Motard-Bélanger, A., A. Charest, G. Grenier, P. Paquin, P. Y. Chouinard, S. Lemieux, P. Couture, and B. Lamarche. 2008. Study of the effect of trans fatty acids from ruminants on blood lipids and other risk factors for cardiovascular disease. Am. J. Clin. Nutr. $87: 593-599$.

Mozaffarian, D., M. B. Katan, A. Ascherio, M. J. Stampfer, and W. C. Willett. 2006. Trans fatty acids and cardiovascular disease. N. Engl. J. Med. 354:1601-1613.

Palmquist, D. L., A. L. Lock, K. J. Shingfield, and D. E. Bauman. 2005. Biosynthesis of conjugated linoleic acid in ruminants and humans. Pages 179-217 in Advances in Food and Nutrition Research. Vol. 50. Elsevier Academic Press, London, UK.
Piperova, L. S., J. Sampugna, B. B. Teter, K. F. Kalscheur, M. P. Yurawecz, Y. Ku, K. M. Morehouse, and R. A. Erdman. 2002. Duodenal and milk trans octadecenoic acid and conjugated linoleic acid (CLA) isomers indicate that postabsorptive synthesis is the predominant source of cis-9-containing CLA in lactating dairy cows. J. Nutr. 132:1235-1241.

Proell, J. M., E. E. Mosley, G. L. Powell, and T. C. Jenkins. 2002. Isomerization of stable isotopically labelled elaidic acid to cis and trans monoenes by ruminal microbes. J. Lipid Res. 43:2072-2076.

Seidel, C., T. Deufel, and G. Jahreis. 2005. Effect of fat-modified dairy products on blood lipids in humans in comparison with other fats. Ann. Nutr. Metab. 49:42-48.

Shingfield, K. J., S. Ahvenjärvi, V. Toivonen, A. Ärölä, K. V. V. Nurmela, P. Huhtanen, and J. M. Griinari. 2003. Effect of dietary fish oil on biohydrogenation of fatty acids and milk fatty acid content in cows. Ann. Sci. 77:165-179.

Shingfield, K. J., C. K. Reynolds, B. Lupoli, V. Toivonen, P. Delmonte, J. M. Griinari, A. S. Grandison, and D. E. Beever. 2005. Effect of forage type and proportion of concentrate in the diet on milk fatty acid composition in cows given sunflower oil and fish oil. Ann. Sci. 80:225-238.

Sukhija, P. S., and D. L. Palmquist. 1990. Dissociation of calcium soaps of long-chain fatty acids in rumen fluid. J. Dairy Sci. 73:1784-1787.

Tholstrup, T., B. Sandström, J. E. Hermansen, and G. Hølmer. 1998. Effect of modified dairy fat on postprandial and fasting plasma lipids and lipoproteins in healthy young men. Lipids 33:11-21.

Van Nevel, C. J., and D. I. Demeyer. 1996. Influence of $\mathrm{pH}$ on lipolysis and biohydrogenation of soybean oil by rumen contents in vitro. Reprod. Nutr. Dev. 36:53-63.

Vlaeminck, B., V. Fievez, A. R. J. Cabrita, A. J. M. Fonseca, and R. J. Dewhurst. 2006. Factors affecting odd- and branched-chain fatty acids in milk: A review. Anim. Feed Sci. Technol. 131:389-417.

Wood, R., K. Kubena, B. O'Brien, S. Tseng, and G. Martin. 1993 Effect of butter, mono- and polyunsaturated fatty acid-enriched butter, trans fatty acid margarine, and zero trans fatty acid margarine on serum lipids and lipoproteins in healthy men. J. Lipid Res. 34:1-11. 